\title{
GPS-only, GLONASS-only and Combined GPS+GLONASS Absolute Positioning under Different Sky View Conditions
}

\author{
Kamil MACIUK
}

\begin{abstract}
In recent years GNSS measurements techniques obtained a majority role in civil engineering and other technical fields. An example of this is the monitoring of both natural phenomena and manmade constructions. The main advantages of satellite positioning, as opposite to classical surveying techniques like levelling or total stations, are continuous long term observations and economic advantage, due to the lack of measurement crew. Currently, apart from GPS, other satellite systems in use like GLONASS or Galileo are becoming more important. Together with development of GNSS measurements for satellite positioning in open areas, also urban and mountainous areas can be measured. This kind of areas was excluded from measurements with single GNSS system, due to the lack of the required minimum number of visible satellites. Multi-GNSS (hybrid, integrated - usage of more than one satellite navigation system in measurements) positioning, currently providing more than 80 active satellites, opens new grounds for satellite measurements. Among measurement methods PPP is the most developing one since the beginning of $21^{\text {st }}$ century. Main PPP advantages are: independence from reference station, lack of limitation of use to certain areas and global coverage with consistent, homogenous solutions. The paper shows the results of 90-days continuous static observations processed with the usage of PPP technique on simulated different sky view conditions. Measurements were made on points with known coordinates as a construction simulation. The data were processed in three modes: GPS-only, GLONASS-only and hybrid GNSS (GPS+GLONASS) using three different elevation cut-off angles. Accuracy analyses were carried out on the basis of final, daily EPN solutions at the observation time.
\end{abstract}

Keywords: absolute positioning; engineering; GLONASS; GNSS; GPS; PPP

\section{INTRODUCTION}

In the last years due to expansion of other than GPS (Global Positioning System) systems integrated GNSS (Global Navigation Satellite System) become standard of satellite measurements. First GPS satellite was launched in 1978 and the system became fully operable in 1995 as a first GNSS. Fully operable means to achieve nominal planned number of satellites active on the orbit. Currently besides GPS, also GLONASS (transliteration from Russian is GLObalnaya NAvigatsionnaya Sputnikovaya Sistema or Global Navigation Satellite System) is fully operable, next to them partly operable are Chinese BeiDou and European Galileo. Currently there are more than 80 GNSS satellites available [1]. Greater number of simultaneously visible satellites theoretically brings many advantages. First of all, the usage of multiple navigation systems helps to increase the quality and accuracy especially in real time positioning [2]. It helps in a proper way to weight signals proportionally to its strength and quality, or even eliminate the less accurate satellites. Greater number of available satellites also helps to shorten the duration of the session, especially for most accurate measurements. Also it makes available areas so far unavailable for GPS-only observations due to the lack of necessary number of simultaneously tracking satellites [3] (Figs. 1 and 2). There are also disadvantages associated with the usage of integrated GNSS measurements. The main disadvantage includes different reference frames, the time scales and inter-channels are biased [4].

There are two types of GNSS positioning techniques in use: absolute and relative positioning. According to construction and principle of GNSS operation vertical component accuracy is three times smaller than horizontal ones [5]. Since the beginning of GNSS positioning most accurate and common in use is relative (differential) positioning. This method is based on information from reference station or group of reference stations with known coordinates. By observation's differentiation most of errors are reduced so this method is more precise than absolute positioning after taking into account reference station's error. The best known and most commonly used differential positioning method is RTK (Real Time Kinematic) technique. Static measurements within a millimetre accuracy can be achieved for respectively long sessions length and short vectors. For extremely short baselines (<several hundred metres) in 24-hours session, the accuracy could be less than a millimetre [6]. On the other hand, using single vector of $500-600 \mathrm{~km}$ with one hour observation session allows us to achieve results better than $10 \mathrm{~cm} \mathrm{3D} \mathrm{[7].} \mathrm{As} \mathrm{the} \mathrm{practice} \mathrm{shows} \mathrm{adding}$ GLONASS observations to GPS in network processing does not significantly change accuracy of any coordinates. In some cases adding GLONASS signals improves solution's quality for others, GPS-only solutions were slightly better [8].

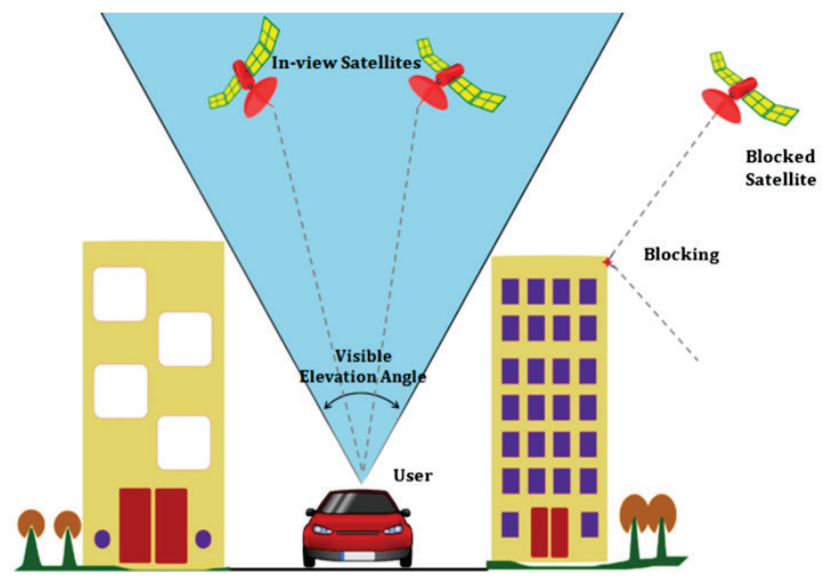

Figure 1 Satellite blocking in urban canyons [12]

A relatively new GNSS positioning technique, used for about 15 years is PPP (Precise Point Positioning). PPP is an absolute method, independent from the reference station and errors connected with it, but this method requires a dual frequency receiver and the use of precise 
products. The accuracy and reliability of GNSS PPP have been conducted so far by various authors. Daily observations without horizon obstacles generally have coordinates repeatability at $2-3 \mathrm{~mm}$ level for horizontal coordinates and 5-6 $\mathrm{mm}$ for height [9]. GPS+GLONASS observations in kinematic mode were conducted by [10]. The authors concluded that accuracy of combined GPS+GLONASS measurements is compared to GPS-only ones and it is clearly visible that GLONASS-only accuracy was lower than other results. Combined GPS, GLONASS, BeiDou and Galileo static positioning results show no significant improvement of accuracy relating to single GNSS positioning, but the convergence time has been improved [11].

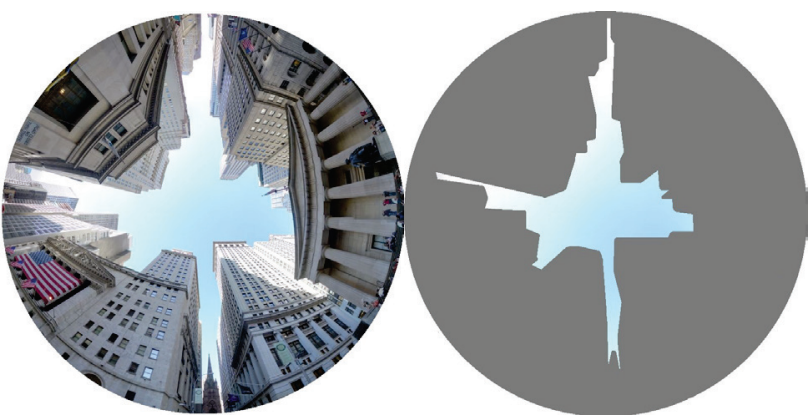

Figure 2 The example of the visible part of sky on an urban area [15]

In another elaboration static PPP positioning in GPS+GLONASS mode shows slightly better results comparing to GPS-only both for horizontal and vertical coordinates [13]. Similar proposals mention authors [14], for $24 \mathrm{~h}$ and $8 \mathrm{~h}$ observations all (GPS-only, GLONASSonly and GPS+GLONASS) results are at the same accuracy level. For shorter observations periods GPS only solutions provide better accuracy compared with GLONASS-only equivalents.

Nowadays satellite measurements techniques are in use for a wide range of applications like: landslides, mining areas monitoring, crustal deformations or constructions monitoring. Currently the most common use refers to relative positioning especially RTK e.g. in bridges [16] or skyscrapers [17] monitoring for short intraday observation sessions (Fig. 3).

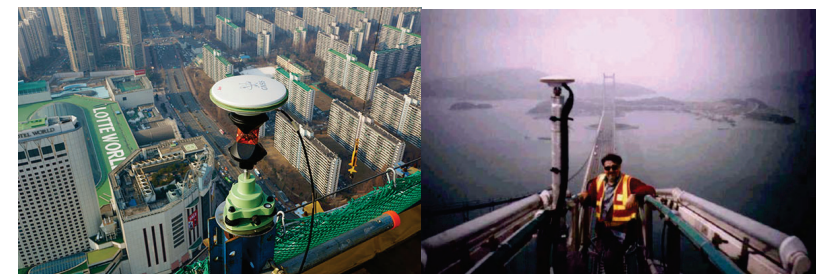

Figure 3 GPS monitoring antennas on a skyscraper [18] and bridge [19]

For a long term stability monitoring (several days, months or permanent monitoring) various types of static measurements (fast/rapid static, "stop-and-go") or RTK methods are generally in use. So far monitoring PPP technique was used only for natural phenomena and there are a lot of publications considering static and kinematic PPP mode e.g. [20, 21]. Deformation monitoring in simulation platform based on kinematic PPP observations in four different modes, was made [22]. In the best mode RMSE (Root Mean Squared Error) of horizontal coordinates was $1,5 \mathrm{~cm}$, and for vertical coordinate $2,2 \mathrm{~cm}$. Accuracy of daily PPP observations with the usage in GPS-only, BeiDou-only and hybrid GPS BeiDou mode were made in [23]. The least accurate were BeiDou only observations (3D RMSE 3,7 cm). GPS-only and hybrid mode had the same accuracy level (respectively $1,6$ and $1,5 \mathrm{~cm})$

\section{PRECISE POINT POSITIONING}

Standard market GPS receiver using code observations in standalone mode accuracy can be up to a few meters. Independence from the influence of errors transferred from the reference station is one of the best PPP advantages. It makes from PPP a great tool for research of phenomenon connected with the movement of earth crust [24]. In modelling PPP observations, beside the necessity of reference station, satellite clock corrections are not estimated, but assumed to be known. Satellite clock corrections are introduced into processing together with Earth orientation parameters and orbit information by precise products from e.g. IGS or CODE. Therefore estimated parameters are station clock corrections, troposphere parameters and coordinates. PPP observation equations of respective code and phase on dual-frequency GPS/GLONASS receiver on L1 and L2 is defined as $[25,26]$ :

$$
\begin{aligned}
P_{i}^{g} & =\rho_{g}+c d t^{g}-c d T^{g}+d_{o r b}^{g}+ \\
& +d_{\text {trop }}^{g}+d_{\text {ion } / P_{i}}^{g}+d_{m u l t i / P_{i}}^{g}+\varepsilon_{P_{i}}^{g} \\
\Phi_{i}^{g} & =\rho_{g}+c d t^{g}-c d T^{g}+d_{o r b}^{g}+d_{\text {trop }}^{g}- \\
& -d_{\text {ion } / \Phi_{i}}^{g}+d_{\text {multi } / \Phi_{i}}^{g}-\lambda_{i}^{g} N_{i}^{g}+\varepsilon_{\Phi_{i}}^{g} \\
P_{i}^{r}= & \rho_{r}+c d t^{r}-c d T^{r}+d_{o r b}^{r}+ \\
& +d_{\text {trop }}^{r}+d_{\text {ion } / P_{i}}^{r}+d_{m u l t i / P_{i}}^{r}+\varepsilon_{P_{i}}^{r} \\
\Phi_{i}^{r} & =\rho_{r}+c d t^{r}-c d T^{g}+d_{o r b}^{r}+d_{\text {trop }}^{r}- \\
& -d_{\text {ion } / \Phi_{i}}^{r}+d_{m u l t i / \Phi_{i}}^{r}-\lambda_{i}^{r} N_{i}^{r}+\varepsilon_{\Phi_{i}}^{r}
\end{aligned}
$$

where subscripts $g$ and $r$ refer to GPS and GLONASS satellites respectively:

$P_{i}$ - is the measured pseudorange on $L_{i}(\mathrm{~m})$

$\Phi_{i}$ - is the measured carrier phase on $L_{i}(\mathrm{~m})$

$\rho$ - is the true geometric range $(\mathrm{m})$

$c-$ is the speed of light $(\mathrm{m} / \mathrm{s})$

$d t$ - is the receiver clock error (s)

$d T$ - is the satellite clock error (s)

$\lambda_{i}$ - is the wavelength on $L_{i}(\mathrm{~m} /$ cycle $)$

$N_{i}$ - is the integer phase ambiguity on $L_{i}(\mathrm{~m} /$ cycle $)$

$\varepsilon$ - is the measurement noise (m)

$d_{o r b}$ - is the satellite orbit error (m)

$d_{\text {trop }}$ - is the tropospheric delay $(\mathrm{m})$

$d_{i o n / L i}$ - is the ionospheric delay on $L_{i}(\mathrm{~m})$

$d_{\text {multi/Pi }}$ - is the multipath effect in the measured pseudorange on $L_{i}(\mathrm{~m})$

$d_{\text {multi/कi }}$ - is the multipath effect in the measured carrier phase on $L_{i}(\mathrm{~m})$ 
In Eqs. (3) and (4) the system time difference must be also considered for mixed GPS/GLONASS measurements processing [27]:

$d t=t-t_{\text {sys }}$

where $t_{s y s}$ denotes either GPS system time $\left(t_{G P S}\right)$ for GPS observations or GLONASS system time ( $t_{\text {GLONASSS }}$ ) for GLONASS observations. Un-differenced ionosphere-free code and carrier phase combination, called L3, is widely used in PPP model. It can be written as [28]:

$$
L_{3}=\frac{1}{f_{1}^{2}-f_{2}^{2}}\left(f_{1}^{2} L_{1}-f_{2}^{2} L_{2}\right)
$$

Its linear combination is appropriate for PPP, because it eliminates first order ionospheric path delay. Corresponding combinations for code measurements are defined as:

$$
P_{3}=\frac{1}{f_{1}^{2}-f_{2}^{2}}\left(f_{1}^{2} P_{1}-f_{2}^{2} P_{2}\right)
$$

After taking into account Eq. (5), (6), (7) into Eq. (3) and (4) following [25]:

$$
\begin{aligned}
& P_{I F}^{g}=\frac{f_{g_{1}}^{2} P_{1}^{g}-f_{g_{2}}^{2} P_{2}^{g}}{f_{g_{1}}^{2}-f_{g_{2}}^{2}}=\rho_{g}+c d t^{g}+d_{\text {trop }}^{g}+\varepsilon_{P_{I F}}^{g} \\
& \Phi_{I F}^{g}=\frac{f_{g_{1}}^{2} \Phi_{1}^{g}-f_{g_{2}}^{2} \Phi_{2}^{g}}{f_{g_{1}}^{2}-f_{g_{2}}^{2}}=\rho_{g}+c d t^{g}+d_{\text {trop }}^{g}+N_{I F}^{g}+\varepsilon_{\Phi_{I F}}^{g} \\
& P_{I F}^{r}=\frac{f_{r_{1}}^{2} P_{1}^{r}-f_{r_{2}}^{2} P_{2}^{r}}{f_{r_{1}}^{2}-f_{r_{2}}^{2}}=r_{r}+c d t^{g}+c d t_{\text {sys }}+d_{\text {trop }}^{r}+e_{P_{I F}}^{r} \\
& \Phi_{I F}^{r}=\frac{f_{r_{1}}^{2} \Phi_{1}^{r}-f_{r_{2}}^{2} \Phi_{2}^{r}}{f_{r_{1}}^{2}-f_{r_{2}}^{2}}=\rho_{r}+c d t^{g}+c d t_{\text {sys }}+d_{t r o p}^{r}+N_{I F}^{r}+\varepsilon_{\Phi_{I F}}^{r}
\end{aligned}
$$

where subscripts $g$ and $r$ refers to GPS and GLONASS respectively:

$P_{I F}$ - is the ionosphere-free code combination (m)

$\Phi_{I F}$ - is the ionosphere-free phase combination (m)

$f_{i}$ - is the frequency of $L_{i}(\mathrm{~Hz})$

$N_{I F}$ - is the combined ambiguity term (m)

$\varepsilon_{I F}$ - measurement noise, multipath as well as other residual errors $(\mathrm{m})$

For processing PPP a minimum of five satellites tracked at the same time is needed. Observations from five satellites are used to determine three coordinates, receiver's clock error and tropospheric delay. Research shows that, depending on session length PPP, $<1 \mathrm{~cm}$ accuracy can be achieved [29]. Problems of GPS/GLONASS combined processing were discussed in detail by e.g. [30].

\section{METHODOLOGY}

To observe infrastructure settlement, superstructure deformation and to detect structural deficiencies and damage trends, monitoring should be started in the early stage, just after structure completion. In this paper, the author put through simulation of long-term construction monitoring in different sky view conditions. As shown in Fig. 2 currently on urban areas especially for not tall buildings this kind of field conditions is becoming more and more frequent. Processing was made at two EPN stations to compare repeatability one to another. Stations are located on the territory of Poland: ZYWI (Zywiec, $49^{\circ} 41^{\prime} \mathrm{N}, 1^{\circ} 12^{\prime} \mathrm{E}$ ) and WROC (Wrocław, $51^{\circ} 7^{\prime} \mathrm{N}$, $\left.17^{\circ} 3^{\prime} \mathrm{E}\right)$. Both stations were equipped with dual frequency GNSS (GPS+GLONASS) receivers. Receiver Trimble NETR5, antenna Trimble TRM55971.00 TZGD on ZYWI and receiver Leica GRX1200GGPRO with antenna LEIAT504GG LEIS on WROC station. GPS-only, GLONASS-only and combined GNSS (GPS+GLONASS) data processing was made using Bernese GNSS Software 5.2. Processing parameters were:

- $\quad$ orbits - final IGS

- ionosphere model - CODE $2 \mathrm{~h}$

- troposphere model - Neil

- daily DCB files - CODE

- Earth Orientation Parameters - CODE

- satellites clock correction - 30s IGS

- $\quad$ antennas calibration model - IGS08

- ambiguities resolution - QIF (Quasi-Ionosphere Free)

Research refers to the accuracy of successive 90 daily observation sessions with $30 \mathrm{~s}$ sampling interval between $1^{\text {st }}$ January and $31^{\text {st }}$ March. Accuracy analysis was made on the basis of final daily EPN solutions, referring to the observation time. Cartesian coordinates were transformed to topocentric coordinates NEU by the formula (12):

$\left[\begin{array}{c}N \\ E \\ U\end{array}\right]=\left[\begin{array}{ccc}-\sin \phi_{i} \cos \lambda_{i} & -\sin \phi_{i} \sin \lambda_{i} & \cos \phi_{i} \\ -\sin \lambda_{i} & \cos \lambda_{i} & 0 \\ \cos \phi_{i} \cos \lambda_{i} & \cos \phi_{i} \sin \lambda_{i} & \sin \phi_{i}\end{array}\right]\left[\begin{array}{c}d X_{i} \\ d Y_{i} \\ d Z_{i}\end{array}\right]$

where $d X_{i}=X_{i}-\hat{X}, \quad d Y_{i}=Y_{i}-\hat{Y} \quad$ and $\quad d Z_{i}=Z_{i}-\hat{Z}$. Coordinates' residuals were calculated as mean absolute differences according to Eq. (13):

$$
\bar{x}=\frac{\sum_{i=1}^{n}\left|x_{i}-\hat{x}\right|}{n}
$$

and standard deviations Eq. (14):

$\sigma_{\bar{x}}=\sqrt{\frac{\sum_{i=1}^{n}\left(x_{i}-\hat{x}\right)^{2}}{n}}$

where:

$\hat{x}$ - reference value from EPN coordinates

$\bar{x}$ - mean deviation of $x$ coordinate $(\mathrm{N}, \mathrm{E}$ and $\mathrm{U})$ 
$x_{i}$ - value of $i$ observation

$n$ - number of observations (here 90 daily solutions)

As research shows, minimal elevation mask is one of the factors that influence the accuracy of measurements the most [31]. Each of GPS-only, GLONASS-only and GNSS processing were made in three different minimal elevation cut-off angles: $10^{\circ}, 25^{\circ}$ and $30^{\circ}$. Tab. 1 consists of the collation of sky accessibility above the observer, depending on the elevation cut-off angle.

Table 1 Sky visibility according to the cut-off angle
\begin{tabular}{|l|c|c|c|}
\hline Cut-off angle & $10^{\circ}$ & $25^{\circ}$ & $40^{\circ}$ \\
\hline Sky visibility & $79,0 \%$ & $52,2 \%$ & $30,9 \%$ \\
\hline
\end{tabular}

Value $10^{\circ}$ of minimal cut-off angle is assumed as a recommendation for the application in PPP [32]. It eliminates observations with the biggest noise, multipath effect and minimizes cycle slips [33]. Two other minimal elevations of cut-off angles are simulations of urban areas with very large sky obstructions.

\section{RESULTS AND DISCUSSION}

Increasing elevation of the cut-off angle reduces visibility of least accurate satellites, but decreases the number of observations. Fig. 4 presents tracked satellites on station WROC of $1^{\text {st }}$ January for $10^{\circ}$ and $40^{\circ}$ elevation cut-off angles. For $10^{\circ}$ elevation cut-off angle for all day mean number of visible GPS and GLONASS and GNSS satellites are respectively 8,5,6,0 and 14,5.
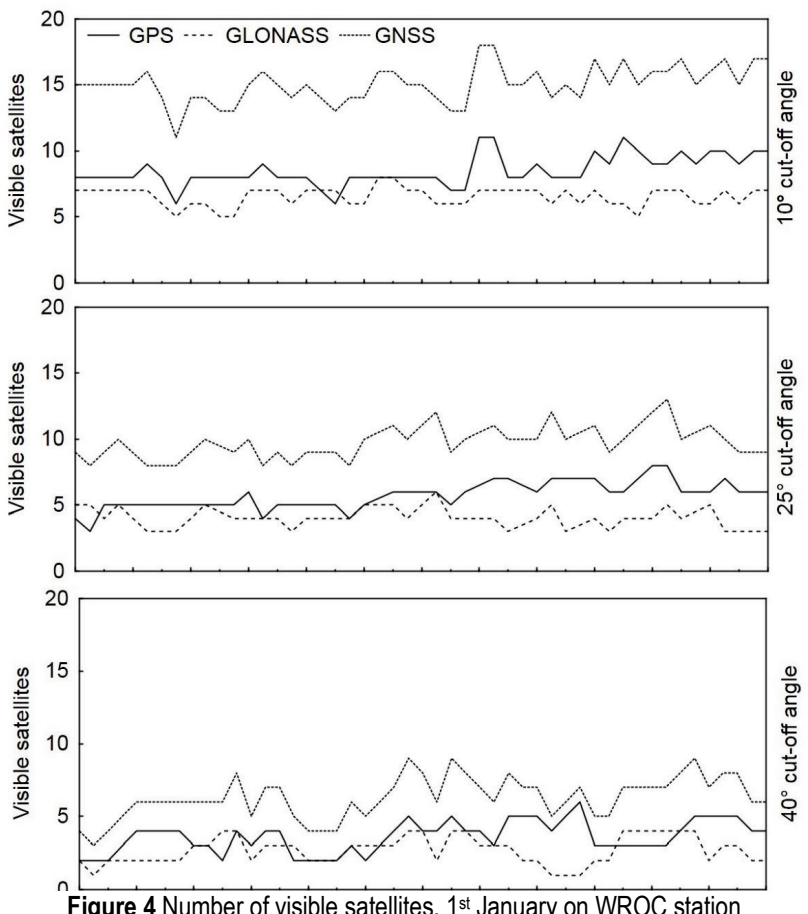

For $10^{\circ}$ cut-off angle mean numbers of GPS, GLONASS and GNSS satellites are 5,7, 4,1 and 9,8 respectively. In case of last elevation cut-off angle $(<70 \%$ sky visibility) mean number of GPS, GLONASS and GNSS satellites is respectively 3,6, 2,7 and 6,3. Fig. 4 shows that at mean latitudes (ZYWI $49^{\circ} 41^{\prime} \mathrm{N}$, WROC $51^{\circ} 7^{\prime} \mathrm{N}$ ) due to construction of global navigation satellite systems number of visible satellites dramatically fall even in small elevation angles.

Dimensionless DOP (Dilution of precision) coefficients represents geometric configuration of satellites and it is in correlation with possible accuracy to achieve. Theoretically, the smaller the DOPs, the better accuracy achieved. It is assumed that for precise measurements PDOP coefficient should not exceed value 2-3. Fig. 5 shows PDOP (Position 3D DOP) on WROC station for $40^{\circ}$ cut-off angle mean GNSS PDOP was 10,8 , max exceeds 70 so it was not illustrated.

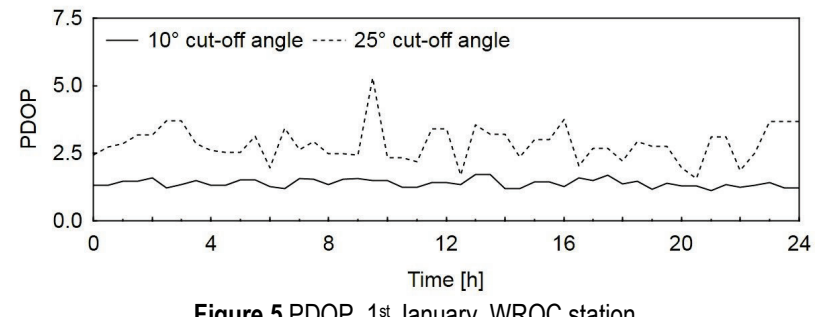

Figure 5 PDOP, $1^{\text {st }}$ January, WROC station

In case of $10^{\circ}$ and $25^{\circ}$ minimum PDOP values were respectively 1,1 and 1,6, maximum 1,7 and 5,3 and mean values 1,4 and 2,9. It clearly indicates that precise results for daily sessions can be achieved with usage of $10^{\circ}$ and $25^{\circ}$ cut-off angles. In some cases even $40^{\circ}$ cut-off angles can assure precise results but such observation sessions must be planned in advance or measurement duration has to be long enough.

Fig. 6 shows North-East coordinates' residuals of the analysed stations. Clearly visible accuracy dispersion is related to magnitude of cut-off angle. The most accurate results on both stations were obtained at $10^{\circ}$ cut-off angle. In this case residuals do not overstep $2 \mathrm{~cm}$. For $25^{\circ}$ minimal cut-off elevation, beside GLONASS-only results, most residuals do not exceed $2 \mathrm{~cm}$. Similar in case of $40^{\circ}$ cut-off angle, beside GLONASS-only results, most results are within $3 \mathrm{~cm}$ accuracy. Analysing results, because the satellite system used the less accurate in each case, were data based on GLONASS-only measurements. Results with usage of GPS-only and GNSS results are similar one to another in each case with no significant differences.

The course of Up component residuals is similar to the horizontal ones - the most accurate results were achieved through the usage of GPS-only and GNSS signals (Fig. 7). In each case GLONASS-only results are the worst ones, even in the slightest sky obstruction there are single $>10 \mathrm{~cm}$ error results. GPS only and GNSS results are very similar at each station and each cut-off angle, and in this case there is no single accidental coordinate deviation. Phenomena described in this paragraph might be explained by algorithms applied in the software for GLONASS ambiguities resolution. It is the result of inter-frequency biases caused by division multiple access technique of GLONASS signals, which causes fixing GLONASS PPP ambiguities difficult [34]. Compared to GPS, the resolved GLONASS ambiguities are characterized by lower quality, therefore GLONASS solutions have the accuracy lower than the GPS ones. Similar conclusions for $24 \mathrm{~h}$ GPS and GPS/GLONASS observations were reached by e.g. [35]. 

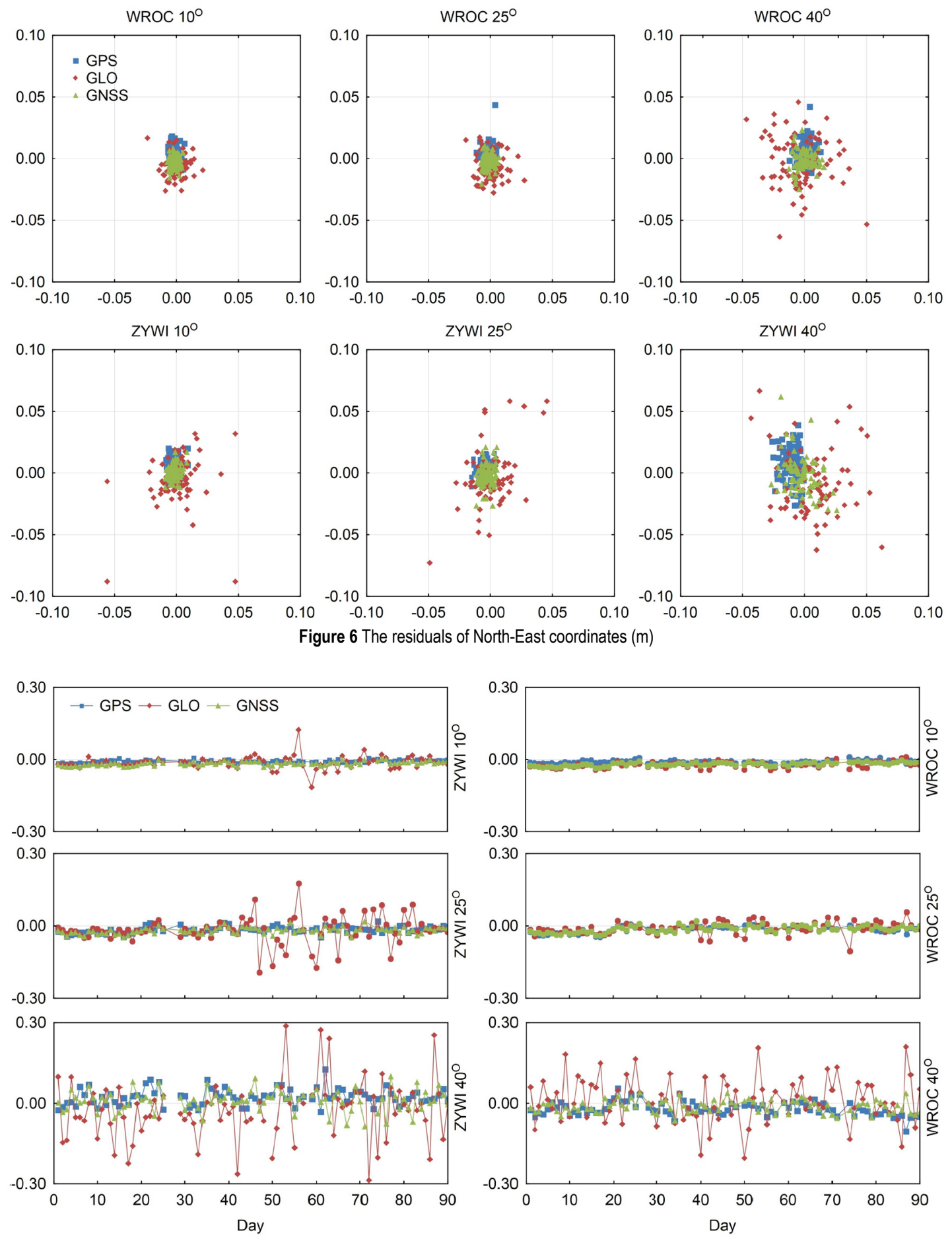

Figure 7 The residuals of Up coordinate $(\mathrm{m})$

For better understanding of the results, Tab. 2 presents the accuracy analysis - mean, absolute residuals and standard deviations of final coordinates. Rows are divided by cut-off angles $\left(10^{\circ}, 25^{\circ}, 40^{\circ}\right)$ and system in use (GPS, GLO - GLONASS, GNSS - GPS+GLONASS). Columns are divided by stations (WROC, ZYWI) and coordinates $(x, y, z)$. The odd-numbered row-panels shows mean absolute residuals of each coordinates ( $x, y, z$ respectively), while the even-numbered row-panels show corresponding standard deviations. It is clearly visible that in each case the less accurate are GLONASS only measurements. GPS-only and GNSS results are similar in most cases. In some cases, more accurate and precise are single GPS results in other two-systems GNSS results.

For better understanding of the results, Tab. 2 presents the accuracy analysis - mean, absolute residuals and standard deviations of final coordinates. Rows are divided by cut-off angles $\left(10^{\circ}, 25^{\circ}, 40^{\circ}\right)$ and system in use (GPS, GLO - GLONASS, GNSS - GPS+GLONASS). Columns are divided by stations (WROC, ZYWI) and coordinates $(x, y, z)$. The odd-numbered row-panels shows mean absolute residuals of each coordinate $(x, y, z$ respectively), while the even-numbered row-panels show corresponding standard deviations. It is clearly visible that in each case the less accurate are GLONASS only 
measurements. GPS-only and GNSS results are similar in most cases. In some cases more accurate and precise are single GPS results in other two-systems GNSS results.

\begin{tabular}{|c|c|c|c|c|c|c|c|}
\hline \multirow{3}{*}{ 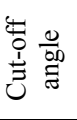 } & \multirow{3}{*}{ 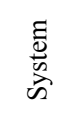 } & \multicolumn{3}{|c|}{ WROC } & \multicolumn{3}{|c|}{ ZYWI } \\
\hline & & $\bar{x}$ & $\bar{y}$ & $\bar{z}$ & $\bar{x}$ & $\bar{y}$ & $\bar{z}$ \\
\hline & & $\sigma_{x}$ & $\sigma_{y}$ & $\sigma_{z}$ & $\sigma_{x}$ & $\sigma_{y}$ & $\sigma_{z}$ \\
\hline \multirow{6}{*}{$10^{\circ}$} & \multirow{2}{*}{ GPS } & 2,7 & 2,7 & 2,7 & 3,3 & 7,7 & 7,6 \\
\hline & & 1,8 & 4,6 & 5,4 & 2,1 & 5,1 & 5,2 \\
\hline & \multirow{2}{*}{ GLO } & 5,0 & 7,8 & 20,7 & 8,0 & 11,0 & 20,1 \\
\hline & & 4,4 & 6,1 & 11,9 & 9,4 & 11,4 & 20,0 \\
\hline & \multirow{2}{*}{ GNSS } & 2,7 & 4,0 & 18,1 & 3,1 & 4,0 & 15,4 \\
\hline & & 1,8 & 3,2 & 8,7 & 2,3 & 3,3 & 8,5 \\
\hline \multirow{6}{*}{$25^{\circ}$} & \multirow{2}{*}{ GPS } & 2,8 & 5,3 & 14,5 & 5,3 & 5,6 & $\mathbf{1 7 , 5}$ \\
\hline & & 2,3 & 5,6 & 12,0 & 3,5 & 4,0 & 11,1 \\
\hline & \multirow{2}{*}{ GLO } & 5,9 & 9,4 & 18,9 & 9,2 & 15,5 & 40,4 \\
\hline & & 5,0 & 6,6 & 17,5 & 9,6 & 17,7 & 42,8 \\
\hline & \multirow{2}{*}{ GNSS } & 3,2 & 4,6 & 14,6 & 4,1 & 5,8 & 19,5 \\
\hline & & 2,1 & 3,7 & 10,9 & 2,8 & 5,4 & 12,1 \\
\hline \multirow{6}{*}{$40^{\circ}$} & \multirow{2}{*}{ GPS } & 1,4 & 8,0 & 24,3 & 5,6 & 18,6 & 24,4 \\
\hline & & 3,1 & 6,5 & 18,4 & 6,2 & 8,9 & 23,6 \\
\hline & \multirow{2}{*}{ GLO } & 12,7 & 15,4 & 61,0 & 15,7 & 19,8 & 81,1 \\
\hline & & 11,3 & 12,4 & 53,0 & 13,4 & 15,5 & 85,2 \\
\hline & \multirow{2}{*}{ GNSS } & 4,8 & 5,8 & 20,1 & 8,3 & 10,5 & 31,6 \\
\hline & & 3,7 & 5,0 & 15,8 & 6,5 & 10,4 & 25,6 \\
\hline
\end{tabular}

Bold fonts in Tab. 2 are the smallest values of residuals and standard deviations for each station and cut-off angle. The most accurate results in majority are with the usage of GPS-only observations; it is seen especially on ZYWI station. Adding GLONASS signals to GPS does not significantly improve the accuracy and in some cases makes it evens worse. Mean residuals show that for horizontal coordinates using PPP technique ensures down to $4 \mathrm{~mm}$ accuracy (GNSS mode), in case of Up coordinate it is $7-20 \mathrm{~mm}$ (all modes) for $10^{\circ}$ cut-off angle.

In case of $25^{\circ}$ cut-off elevation horizontal coordinates and height are determined with 3-6 mm (GPS-only and GNSS) and 15-20 $\mathrm{mm}$ (GPS-only and GNSS) respectively. At $40^{\circ}$ cut-off elevation horizontal coordinates were determined at 5-11 $\mathrm{mm}$ (GNSS) accuracy and height at $24 \mathrm{~mm}$ (GPS-only).

\section{CONCLUSIONS}

Growing number of available GNSS satellites activate new standard in satellite techniques. New signals added to the existing GPS signal make a possible tool for the improvement of accuracy and quality of measurements. The development of global navigation satellite signals entails also progress in solutions algorithms. Performed research ran on GPS-only, GLONASS-only and hybrid GNSS daily static observations with usage of PPP technique in different sky visibility level. Research shows that currently existing software does not improve significantly results comparing GPS-only solutions with multi-GNSS. Adding GLONASS signals to GPS does not affect noticeable improvement of coordinates' accuracy and in some cases even caused accuracy's deterioration. Single GLONASSonly solutions are loaded by the biggest errors and due to that are not recommended for precise purposes. The author shows that daily measurements with usage of PPP technique provides $<1 \mathrm{~cm}$ accuracy. In future additional enhancement in software's algorithms should certainly improve the GNSS quality, especially in the case more than two GNSS systems are used.

\section{ACKNOWLEDGEMENTS}

The paper is the result of research carried out within statutory research no 11.11.150.444 and grant 15.11.150.397 in the Department of Integrated Geodesy and Cartography, Faculty of Mining Surveying and Environmental Engineering, AGH University of Science and Technology.

\section{REFERENCES}

[1] ftp://ftp.trimble.com/pub/eph/almanac.alm (13.03.2017).

[2] Pirti, A. (2016). The seasonal effects of deciduous tree foliage in CORS-GNSS measurements (VRS/FKP). Tehnicki vjesnik - Technical Gazette, 23(3), 769774. https://doi.org/10.17559/TV-20150301214046

[3] Won D. H., Lee E., Heo M., Sung S., Lee J., \& Lee Y. J. (2014). GNSS integration with vision-based navigation for low GNSS visibility conditions. GPS Solutions, 18(2), 177187. https://doi.org/10.1007/s10291-013-0318-8

[4] Al-Shaery A., Zhang S., \& Rizos C. (2015). An enhanced calibration method of GLONASS inter-channel bias for GNSS RTK. GPS Solutions, 17(2), 165-173. https://doi.org/10.1007/s10291-012-0269-5

[5] Witchayangkoon, B. (2000). Elements of GPS precise point positioning. The University of Maine, p. 286.

[6] Wang, G. (2011). GPS Landslide Monitoring: Single Base vs. Network Solutions - A case study based on the Puerto Rico and Virgin Islands Permanent GPS Network. Journal of Geodetic Science, 3(1), 191-203. https://doi.org/10.2478/v10156-010-0022-3

[7] Jie, Z., Fei, L., Weiming, T., \& Lifeng, G. (2013). Crossocean GPS long distance rapid static positioning methods. Geodesy and Geodynamics, 4(1), 23-28. https://doi.org/10.3724/SP.J.1246.2013.01023

[8] Sisman, Y., Elevli, S., \& Sisman, A. (2014). A statistical analysis of GPS positioning using experimental design. Acta Geodaetica et Geophysica, 49(3), 343-355. https://doi.org/10.1007/s40328-014-0053-9

[9] Ge, M., Gendt, G., Rothacher, M., Shi, C., \& Liu, J. (2008). Resolution of GPS carrier-phase ambiguities in Precise Point Positioning (PPP) with daily observations. Journal of Geodesy, 82(7), 389-399. https://doi.org/10.1007/s00190-007-0187-4

[10] Rabbou, M. A. \& El-Rabbany, A. (2015). PPP Accuracy Enhancement Using GPS/GLONASS Observations in Kinematic Mode. Positioning, 6(1), 1-6. https://doi.org/10.4236/pos.2015.61001

[11] Lou, Y., Zheng, F., Gu, S., Wang, C., Guo, H., \& Feng, Y. (2016). Multi-GNSS precise point positioning with raw single-frequency and dual-frequency measurement models. GPS Solutions, 20(4), 849-862. https://doi.org/10.1007/s10291-015-0495-8

[12] Tabatabaei, A., Mosavi, M. R., Khavari, A., \& Shahhoseini, H. S. (2017). Reliable Urban Canyon Navigation Solution in GPS and GLONASS Integrated Receiver Using Improved Fuzzy Weighted Least-Square Method. Wireless Personal Communications, 94(4), 3181-3196. https://doi.org/10.1007/s11277-016-3771-1

[13] Liu, Y., Ye, S., Song, W., Lou, Y., \& Gu, S. (2017). Rapid PPP ambiguity resolution using GPS+GLONASS observations. Journal of Geodesy, 91(4), 441-455. https://doi.org/10.1007/s00190-016-0975-9 
[14] Yigit, C. O., Gikas, V., Alcay, S., \& Ceylan, A. (2014). Performance evaluation of short to long term GPS, GLONASS and GPS/GLONASS post-processed PPP. Survey Review, 336(46), 155-166. https://doi.org/10.1179/1752270613Y.0000000068

[15] Wikipedia, Wall Street, https://en.wikiquote.org/wiki/ Wall_Street (13.03.2017).

[16] Wang, Y., Zhai, C., Zhang, Y., \& Gao, W. (2008). A new GPS deformation monitoring algorithm applied to Donghai Bridge. Journal of Shanghai Jiaotong University (Science), 13(2), 216-220. https://doi.org/10.1007/s12204-008-0216-3

[17] Su, J.-Z., Xia, Y., Chen, L., Zhao, X., Zhang, Q.-L., Xu, Y.L., Ding J.-M., Xiong, H.-B., Ma, R.-J., Lv, X.-L., \& Chen, A.-R. (2013). Long-term structural performance monitoring system for the Shanghai Tower. Journal of Civil Structural Health Monitoring, 3(1), 49-61. https://doi.org/10.1007/s13349-012-0034-z

[18] GPS World staff. GNSS monitoring scrapes the sky. GPS World. The Web version (2015), http:/gpsworld.com/gnssmonitoring-scrapes-the-sky. (13.03.2017)

[19] Ogaja, C., Li, X., \& Rizos, C. (2007). Advances in structural monitoring with Global Positioning System technology: 1997-2006. Journal of Applied Geodesy, 3(1), 171-179. https://doi.org/10.1515/jag.2007.019

[20] Wang, G., Kearns, T. J., Yu, J., \& Saenz, G. (2014). A stable reference frame for landslide monitoring using GPS in the Puerto Rico and Virgin Islands region. Landslides, 11(1), 119-129. https://doi.org/10.1007/s10346-013-0428-y

[21] Guo, J.-Y., Yuan, Y.-D., Kong, Q.-L., Li, G.-W., \& Wang, F.-J. (2012). Deformation caused by the 2011 eastern Japan great earthquake monitored using the GPS single-epoch precise point positioning technique. Applied Geophysics, 9(4), 483-493. https://doi.org/10.1007/s11770-012-0360-2

[22] Zheng, Y., Zhang, R., \& Gu, S. (2014). A new PPP algorithm for deformation monitoring with singlefrequency receiver. Journal of Earth System Science, 123(8), 1919-1926. https://doi.org/10.1007/s12040-014-0502-4

[23] Chen, J., Wang, J., Zhang, Y., Yang, S., Chen, Q., \& Gong, X. (2016). Modeling and Assessment of GPS/BDS Combined Precise Point Positioning. Sensors, 16(8), 1151. https://doi.org/10.3390/s16071151

[24] Maciuk, K. (2016). The Study of Seasonal Changes of Permanent Stations Coordinates based on Weekly EPN Solutions. Artificial Satellites, 51(1), 1-18. https://doi.org/10.1515/arsa-2016-0001

[25] Cai, C. \& Gao Y. (2007). Precise Point Positioning Using Combined GPS and GLONASS Observations. Journal of Global Positioning Systems, 6(1), 13-22.

[26] Chen, K. \& Gao, Y. (2005). Real-Time Precise Point Positioning Using Single Frequency Data. Proceedings of ION GNSS-2005, Long Beach, CA, 1514-1523.

[27] Cai, C. \& Gao, Y. (2012). Modeling and assessment of combined GPS/GLONASS precise point positioning. GPS Solutions, 17(2), pp. 223-236. https://doi.org/10.1007/s10291-012-0273-9

[28] Dach, R., Lutz, S., Walser, P., \& Fridez, P. (2015). Bernese GNSS Software Version 5.2, Astronomical Institute, University of Bern, Switzerland, 884.

[29] Wang, G. Q. (2013). Millimeter-accuracy GPS landslide monitoring using Precise Point Positioning with Single Receiver Phase Ambiguity (PPP-SRPA) resolution: a case study in Puerto Rico. Journal of Geodetic Science, 3(1), 2231. https://doi.org/10.2478/jogs-2013-0001

[30] Alcay, S., Inal, C., Yigit, C., \& Yetkin, M. (2012). Comparing GLONASS-only with GPS-only and hybrid positioning in various length of baselines. Acta Geodaetica et Geophysica Hungarica, 47(1), 1-12. https://doi.org/10.1556/AGeod.47.2012.1.1
[31] Sisman, Y. (2014). The optimization of GPS positioning using response surface methodology. Arabian Journal of Geosciences, 7(3), 1223-1231. https://doi.org/10.1007/s12517-013-0834-4

[32] Yu, X. \& Gao, J. (2017). Kinematic Precise Point Positioning Using Multi-Constellation Global Navigation Satellite System (GNSS) Observations. ISPRS International Journal of Geo-Information, 6(1), 6 . https://doi.org/10.3390/ijgi6010006

[33] Soycan, M. (2011). A Quality Evaluation of Precise Point Positioning within the Bernese GPS Software Version 5.0. Arabian Journal for Science and Engineering, 37(1), $147-$ 162. https://doi.org/10.1007/s13369-011-0162-5

[34] Pan, L., Xiaohong, Z., \& Fei, G. (2017). Ambiguity resolved precise point positioning with GPS and BeiDou. Journal of Geodesy, 91(1), 25-40. https://doi.org/10.1007/s00190-016-0935-4

[35] Alcay, S. \& Yigit, C. O. (2016). Network based performance of GPS-only and combined GPS/GLONASS positioning under different sky view conditions. Acta Geodaetica et Geophysica, 1-12. https://doi.org/10.1007/s40328-016-0173-5

\section{Contact information:}

\section{Kamil MACIUK, PhD}

Department of Integrated Geodesy and Cartography Faculty of Mining Surveying and Environmental Engineering AGH University of Science and Technology al. Mickiewicza 30, 30-059 Krakow, Poland E-mail: maciuk@agh.edu.pl 